\title{
Lipid Needs of Preterm Infants: Updated Recommendations
}

\author{
Alexandre Lapillonne, MD, PhD ${ }^{1,2}$, Sharon Groh-Wargo, PhD, LD, RD ${ }^{3}$, Carlos H. Lozano Gonzalez, MD, MPH4, \\ and Ricardo Uauy, MD, $\mathrm{PhD}^{5}$
}

Long-chain polyunsaturated fatty acids (LCPUFAs) are of nutritional interest because they are crucial for normal development of the central nervous system and have potential long-lasting effects that extend beyond the period of dietary insufficiency. Here we review the recent literature and current recommendations regarding LCPUFAs as they pertain to preterm infant nutrition. In particular, findings that relate to fetal accretion, LCPUFA absorption and metabolism, effects on development, and current practices and recommendations have been used to update recommendations for health care providers.

The amounts of long-chain polyunsaturated fatty acids (LCPUFAs) used in early studies were chosen to produce the same concentrations as in term breast milk. This might not be a wise approach for preterm infants, however, particularly for very and extremely preterm infants, whose requirements for LCPUFAs and other nutrients exceed what is normally provided in the small volumes that they are able to tolerate. Recent studies have reported outcome data in preterm infants fed milk with a docosahexaenoic acid (DHA) content 2-3 times higher than the current concentration in infant formulas. Overall, these studies show that providing larger amounts of DHA supplements, especially to the smallest infants, is associated with better neurologic outcomes in early life. We emphasize that current nutritional management might not provide sufficient amounts of preformed DHA during the parenteral and enteral nutrition periods and in very preterm/very low birth weight infants until their due date, and that greater amounts than used routinely likely will be needed to compensate for intestinal malabsorption, DHA oxidation, and early deficit. Research should continue to address the gaps in knowledge and further refine adequate intake for each group of preterm infants. (J Pediatr 2013;162:S37-47).

reterm infants are particularly susceptible to postnatal growth failure and nutrient deficiencies. Dietary lipids provide preterm infants with most of their energy needs. Recent interest has focused on the quality of dietary lipid supply early in life as a major determinant of growth, infant development, and long-term health. In this regard, LCPUFAs are of concern because they are crucial for normal development of the central nervous system development and have the potential for long-lasting effects extending beyond the period of dietary insufficiency. ${ }^{1}$ Furthermore, LCPUFAs also have potentially significant modulatory effects on developmental processes that affect short-term and long-term health outcomes related to growth, body composition, immune and allergic responses, and the prevalence of nutrition-related chronic diseases. ${ }^{1}$

Recommendations for intake of total fat, essential fatty acids (EFAs), and medium-chain triglycerides (MCTs) have not varied over the last decade, and to our knowledge, there are no new data that would cause us to modify the current recommendations. ${ }^{1}$ This is not to say that there have been no new developments in the area of LCPUFAs. Consequently, the aim of this article is to review the recent literature and current recommendations regarding LCPUFAs as they pertain to preterm infant nutrition. In particular, findings related to fetal accretion, LCPUFA absorption and metabolism, effects on development, and current practices and recommendations are used to update recommendations for health care providers.

\section{LCPUFA Fetal Accretion Rate}

When data on intrauterine accretion are available, the amount of nutrient required to attain the mean rate of accretion can be used to estimate the minimum nutrient requirement for preterm infants. When there are adequate bioavailability data on the relative absorption of a nutrient from human milk or infant formulas and on oxidation rate and/or losses, a recommendation can be made regarding the minimum amount for absorption that will result in a net retention rate similar to the intrauterine accretion rate.

\begin{tabular}{|ll|}
\hline ALA & $\alpha$-linolenic acid \\
ARA & Arachidonic acid \\
DHA & Docosahexaenoic acid \\
EFA & Essential fatty acid \\
EPA & Eicosapentaenoic acid \\
LA & Linoleic acid \\
LCPUFA & Long-chain polyunsaturated fatty acid \\
MCT & Medium-chain triglyceride \\
MDI & Mental Development Index \\
\hline
\end{tabular}

From the ${ }^{1}$ Paris Descartes University, Assistance Publique Hôpitaux de Paris Necker Hospital, Paris, France; ${ }^{2}$ Children's Nutrition Research Center, Baylor College of Medicine, Houston, TX; ${ }^{3}$ Case Western Reserve University, MetroHealth Medical Center, Cleveland, $\mathrm{OH} ;{ }^{4}$ Academia Mexicana de Pediatría, Pediatría Medicina Perinatal, Monterrey, Mexico; and 5 Institute of Nutrition and Food Technology, University of Chile, Santiago, Chile

Please see the Author Disclosures at the end of this article. 
Attention so far has focused mainly on DHA accumulation in the central nervous system. Whether the brain is protected when availability of DHA is limited is not known, but the ease with which fetal brain DHA is altered by maternal dietary n-3 fatty acid intake suggests that the membrane lipid composition of the fetal brain is sensitive to changes in DHA supply. ${ }^{2}$ Because most LCPUFAs accumulate in white adipose tissue and, to a lesser extent, in lean mass and the liver, ${ }^{3}$ it is important to consider the accumulation of DHA and other LCPUFAs in all relevant organs.

Analyses of fetal autopsy tissue yielded the following estimates of intrauterine accretion of LCPUFAs during the last trimester: $106 \mathrm{mg} / \mathrm{kg} /$ day for linoleic acid (LA), $4 \mathrm{mg} / \mathrm{kg} /$ day for $\alpha$-linolenic acid (ALA), $212 \mathrm{mg} / \mathrm{kg} /$ day for arachidonic acid (ARA), and $43 \mathrm{mg} / \mathrm{kg} /$ day for DHA. ${ }^{3}$ It is likely that the accumulation of LCPUFAs is not linear over time during the last trimester of gestation. Thus, using these numbers to calculate an average daily rate of fatty acid accumulation will overestimate or underestimate tissue requirements during specific periods of growth. A more precise estimate of the fetal accretion rate cannot be determined until more data become available.

The placenta selectively favors the transfer of DHA over other fatty acids, including ARA, during the last trimester of pregnancy. ${ }^{4}$ It is generally thought that the fetus does not synthesize LCPUFAs from their precursors at rates sufficient to support an adequate DHA accretion rate. However, evidence from stable isotope studies in preterm infants suggests that ARA and DHA synthesis occurs to some degree at an age when the infant would normally be dependent on placental transfer. ${ }^{5}$ Tracer studies indicate that the rate of ARA synthesis is significantly greater than the rate of DHA synthesis, suggesting that the fetus has a greater ability to regulate ARA supply by de novo synthesis or placental reuptake compared with DHA supply. ${ }^{4}$ Overall, these data suggest that exogenous supply of DHA may be more critical than that of ARA during the perinatal period.

\section{LCPUFA Absorption and Metabolism}

The fetus does not accumulate appreciable amounts of fat until the last trimester of gestation. Thus, postnatally, adipose tissue cannot be a significant source of LCPUFAs for brain growth of preterm infants as it is for term infants. The LCPUFAs used for organ growth, including brain growth, depend on the amount of LCPUFAs supplied exogenously, intestinal absorption of LCPUFAs, and, finally the capacity to synthesize and oxidize LCPUFAs.

Digestion and Absorption of LCPUFAs. Mechanisms of fat absorption and digestion have been reviewed extensively elsewhere. ${ }^{1}$ MCTs and structured lipids (eg, synthetic $\beta$-palmitate) do not fall within the scope of this review, even though they may affect LCPUFA absorption and improve overall fat absorption. Human milk fat is provided in the form of a milk fat globule and consists mainly of triacylglycerols (98\%), phospholipids (1\%), and cholesterol and cholesterol esters $(0.5 \%)$. In breast milk, LCPUFAs are mainly triacylglycerols esterified at the $s n-2$ and $s n-3$ positions and can be part of the phospholipid fraction. ${ }^{6}$ Human milk contains bile salt-stimulated lipase and palmitic acid in the $\beta$ position of the triglyceride molecule. These unique components increase the bioavailability of human milk fat by improving absorption and digestion. However, human milk for preterm infants is often pasteurized to suppress viral and bacterial activity. Heat inactivates bile salt-stimulated lipase and changes the structure of the milk fat globule. These actions may be the reason why feeding pasteurized milk is associated with a $30 \%$ reduction in fat absorption and growth rate. ${ }^{7}$ Fortification of human milk, particularly with calcium, may further impair LCPUFA absorption. Overall, only 70\%$80 \%$ of ARA and DHA from pasteurized breast milk is absorbed by very preterm infants (Table I).

The recombinant form of human bile salt-stimulated lipase significantly increases DHA and ARA absorption when added to pasteurized human milk. ${ }^{8}$ This approach can be potentially beneficial, but the safety, efficacy, and cost-effectiveness of using recombinant human bile saltstimulated lipase as an additive must be fully characterized before routine use can be recommended.

LCPUFAs from fish oils or from single-cell algae are added as triacylglycerols to the fat blend of preterm formulas. DHA in algal oils has a weak positional specificity and contains equal amounts of DHA in the $s n-1, s n-2$, and $s n-3$ positions, unlike the DHA triacylglycerols present in breast milk. These chemical differences may reduce absorption of DHA derived from algal sources. Although fish oil provides DHA with a bond located in the $s n-2$ position, it also contains eicosapentaenoic acid (EPA), which has not yet been proven safe in preterm infants (Table I).

Phospholipids are not a common source of LCPUFAs in preterm formulas. ${ }^{9,10}$ However, it can be speculated that DHA derived from phospholipids offers potential advantages because it: (1) is one of the forms found naturally in human milk; (2) provides ARA and other LCPUFAs; and (3) may be one way to promote brain DHA uptake. ${ }^{11}$

LCPUFA Metabolism by Preterm Infants. Studies using LCPUFA precursors labeled with stable isotopes have demonstrated that LCPUFA synthesis occurs even in small preterm infants. ${ }^{1}$ Using the novel "stable isotope natural abundance" approach, the estimated mean endogenous synthesis of ARA was reported as $27 \mathrm{mg} / \mathrm{kg} /$ day at 1 month and $12 \mathrm{mg} / \mathrm{kg} / \mathrm{day}$ at 7 months, and that of DHA was $13 \mathrm{mg} / \mathrm{kg} /$ day at $1 \mathrm{month}$ and $2 \mathrm{mg} / \mathrm{kg} /$ day at 7 months. ${ }^{12}$ Thus, endogenously synthesized LCPUFAs are insufficient to meet requirements defined by the fetal accretion rate. Whether conversion in human milk-fed preterm infants is similar to that in formula-fed preterm infants, or whether conversion is affected by the supply of dietary EFAs or LCPUFAs, remains to be established.

Recent studies in adult populations have suggested that variability in biochemical and functional central nervous system responses to changes in diet are explained in part by 
Table I. Comparison of intestinal absorption of fatty acids among formulas

\begin{tabular}{|c|c|c|c|c|c|c|c|}
\hline & \multicolumn{4}{|c|}{ Study I* } & \multicolumn{3}{|c|}{ Study $\mathrm{II}^{\dagger}$} \\
\hline & Preterm breast milk & Standard PTF1 & PL PTF & TG-MO PTF & Fortified preterm breast milk & Standard PTF2 & TG-FO PTF \\
\hline \multicolumn{8}{|c|}{$\begin{array}{r}\text { Intestinal absorption } \\
\text { (fatty acids, \%) }\end{array}$} \\
\hline $18: 2 n-6$ & $88.1 \pm 3.0$ & $69.7 \pm 0.3$ & $91.3 \pm 1.7$ & $68.9 \pm 4.0$ & $83.5 \pm 13$ & $97.8 \pm 1.6$ & $95.9 \pm 3.0$ \\
\hline $20: 4 n-6$ & $81.1 \pm 3.6$ & NA & $84.7 \pm 1.7$ & $80.4 \pm 2.3$ & $76.6 \pm 12$ & NA & $75.9 \pm 10.2$ \\
\hline $18: 3 n-3$ & $90.3 \pm 2.6$ & $88.5 \pm 1.5$ & $94.4 \pm 1.1$ & $90.5 \pm 1.6$ & $85.3 \pm 12$ & $98.2 \pm 1.3$ & $96.7 \pm 2.7$ \\
\hline $20: 5 n-3$ & $57.0 \pm 6.9$ & NA & $64.3 \pm 9.5$ & NA & $81.0 \pm 25$ & NA & $92.5 \pm 3.3$ \\
\hline $22: 6 n-3$ & $78.4 \pm 4.0$ & NA & $88.3 \pm 1.8$ & $80.4 \pm 2.3$ & $76.9 \pm 18$ & NA & $94.8 \pm 4.2$ \\
\hline \multicolumn{8}{|c|}{$\begin{array}{l}\text { Metabolizable intake (fatty } \\
\text { acids, } \mathrm{mg} / \mathrm{kg} / \text { day) }\end{array}$} \\
\hline $18: 2 n-6$ & $608 \pm 61$ & $585 \pm 29$ & $601 \pm 13$ & $575 \pm 38$ & $453 \pm 231$ & $906 \pm 213$ & $878 \pm 152$ \\
\hline $20: 4 n-6$ & $26.0 \pm 2.1$ & NA & $16.4 \pm 0.4$ & $40.0 \pm 1.4$ & $20.1 \pm 6$ & NA & $1.7 \pm 0.2$ \\
\hline $18: 3 n-3$ & $35.2 \pm 3.8$ & $64.5 \pm 1.2$ & $51.0 \pm 0.8$ & $64.7 \pm 1.8$ & $29.9 \pm 9.0$ & $80.9 \pm 18.0$ & $54.2 \pm 6.9$ \\
\hline $20: 5 n-3$ & $2.7 \pm 1.0$ & NA & $1.4 \pm 0.4$ & NA & $10.0 \pm 10.0$ & NA & $4.6 \pm 1.0$ \\
\hline $22: 6 n-3$ & $14.1 \pm 1.2$ & NA & $12.0 \pm 0.3$ & $30.6 \pm 1.1$ & $15.9 \pm 7.0$ & NA & $18.2 \pm 3.7$ \\
\hline
\end{tabular}

NA, not applicable; PTF, preterm formula; PL, LCPUFAs from phospholipids; TG-MO PTF, triacylglycerols from microorganisms; TG-FO PTF, triacyglycerols from fish oil.

Shown are intestinal absorption of fatty acids and metabolizable intake of fatty acids at age $\sim 4$ weeks in preterm infants fed exclusively unfortified (study I) or fortified (study II) preterm breast milk, standard preterm formula with no LCPUFAs added (standard PTF1; standard PTF2), preterm formula with LCPUFA TG-MO PTF or from TG-FO PTF, or preterm formula with LCPUFA phospholipids from egg yolk (PL PTF).

${ }^{*}$ Study I: data from Carnielli et al. ${ }^{9}$

†Study II: balance study performed in a subset of 15 preterm infants from Lapillonne et al ${ }^{53}$; postnatal age $\sim 4$ weeks, no significant difference among groups for postnatal age, corrected age, and weight at time of the balance study (Picaud JC et al, unpublished data 2012).

single nucleotide polymorphisms in genes responsible for EFA desaturation. This finding adds complexity to defining LCPUFA requirements and establishing the extent of the effect of the intake other nutrients (eg, LCPUFA precursors, $\mathrm{n}-3 / \mathrm{n}-6$ fatty acid ratio) that affect endogenous LCPUFA synthesis. ${ }^{13}$ These findings explain much of the variance in ARA blood levels, but no association between polymorphism desaturase and DHA levels has yet been identified, suggesting a stronger role for the influence of diet on DHA levels. ${ }^{14,15}$ To our knowledge, there is no similar evidence for preterm infants; however, because the conversion of EFA to LCPUFAs is highly variable, it is likely that the single nucleotide polymorphisms that play a regulatory role in LCPUFA formation may exist in preterm infants as well. In support of this concept, a large interindividual variability in the rate of conversion of EFAs to LCPUFAs has been measured in stable isotope studies of infants. ${ }^{16,17}$

The final step in the synthesis of DHA is considerably more complex than that for ARA. DHA synthesis requires enzymes present in peroxisomes and the endoplasmic reticulum, along with the coordinated movement of fatty acids between these two organelles. A recent study of infants born at term found that, compared with dietary EPA, conversion of EPA to DHA is twice as efficient when EPA is formed from dietary ALA. ${ }^{16}$ Even though conversion of EPA to DHA is less efficient with EPA from the diet compared with EPA formed from ALA, EPA is present in the human milk and relatively well absorbed (Table I). Thus, when estimating ingested "DHA equivalents", it may be appropriate to include approximately $45 \%$ of dietary EPA in the calculation. ${ }^{16}$

None of the estimated retention figures reported to date have taken into account DHA oxidation and endogenous biosynthesis. Present evidence suggests that DHA oxidation may occur in adults as well as in preterm infants. Significant $\beta$-oxidization of DHA in adults was reported recently. ${ }^{18}$ In addition, DHA in plasma phospholipids is decreased in preterm infants who receive $42 \mathrm{mg} / \mathrm{kg} / \mathrm{day}$ of DHA (ie, a dose similar to the theoretical fetal accretion rate) through a lipid emulsion containing fish oil, suggesting that DHA oxidation may be significant. ${ }^{19}$ Furthermore, some DHA oxidation likely occurs in preterm infants, when energy intake does not meet requirements, but the magnitude cannot be estimated based on the available data.

\section{Effects of LCPUFAs Supplementation in Preterm Infants}

Possible effects of LCPUFA supplementation include improving neurologic and visual development. These effects are numerous and significant enough to serve in defining the need for and dosage of LCPUFAs for preterm infants. In contrast, effects on modulation of immune function in preterm infants are too scarce to add sufficient information for estimating requirements.

Data from Experimental Studies. LCPUFAs, particularly DHA, play important roles in central nervous system development. Complex neural functions affected by the composition of dietary fatty acid supply include neurogenesis, photoreceptor differentiation, activation of the visual pigment rhodopsin, protection from oxidative stress, synaptogenesis, activities of multiple enzymes, function of ion channels, neurotransmitter concentrations, and eicosanoid metabolism. ${ }^{20}$ In rodents and nonhuman primates, poor accumulation of retinal and brain DHA leads to abnormal retinal physiology, poor visual acuity, increased duration of visual fixation, and increased stereotyped behaviors and locomotor activity. ${ }^{21}$ The evidence most relevant to the issue of causality showed that control performance levels were 
restored when DHA was added to the diets of animals with severely reduced brain DHA concentrations. ${ }^{21}$ Nevertheless, the magnitude of these effects is not large, despite the fact that the studies were conducted under profound dietary restriction. The relevance of these findings to human development is unclear.

\section{Supplementation with Standard Doses of LCPUFAs.} The effects of LCPUFAs on the developing brain have been reported extensively, ${ }^{22-27}$ and are not reviewed here. Overall, studies in preterm humans indicate possible benefits for retinal and cognitive development, as suggested by greater sensitivity to light on electroretinography, more mature visual acuity, and short-term effects on global developmental outcomes at 6-18 months after DHA supplementation of preterm infant formula. The effects in term infants are weaker but supported by sufficient data to merit consideration of enriching term formulas with LCPUFAs. ${ }^{28,29}$

Interestingly, two recent meta-analyses concluded that the available randomized controlled trials do not show clear benefits of formula supplementation with LCPUFA on neurodevelopment in preterm infants. ${ }^{24,30}$ This finding is somewhat surprising, given that many studies have suggested that LCPUFAs play an important role in development. Several factors may explain these apparent discrepancies, as reviewed previously. ${ }^{3}$ In brief, meta-analyses are designed a priori to classify results as positive or negative relative to a defined clinical issue of interest. In other words, a treatment is deemed either to work and be recommended or to not work and thus not be recommended.

This approach yields the most useful information when a given treatment is well defined. With regard to randomized controlled trials designed to assess the effects of DHA enrichment in preterm formulas, there obviously is extreme variability in study design. The assessment schedule and methodology, dose and source of fatty acid supplementation, and composition of the control formula vary considerably among studies.

Other potential explanations for the difficulty in demonstrating clinical benefits of LCPUFA supplementation in preterm formulas by meta-analysis include variations in study endpoints, selection of relatively mature and healthy preterm infants, timing of the DHA deficit as well as DHA provision, genetic background, maternal DHA status, single versus multiple pregnancy, in utero growth and maturation, and the ability of preterm infants to synthesize DHA from ALA or EPA. It has been shown that the "DHA equivalent," which depends on the rate of conversion and amount of EFA in the diet, has a greater impact than DHA intake on the magnitude of visual acuity response at age 4 months. ${ }^{23}$ Clearly, the magnitude of these factors in modulating DHA status and development in preterm infants is not known and warrants further research.

With regard to safety, adding LCPUFA to preterm formulas has no significant effect on the relative risks of sepsis, necrotizing enterocolitis, retinopathy of prematurity, intraventricular hemorrhage, or bronchopulmonary dys- plasia. ${ }^{24,30}$ It has been 15 years since a fish oil-enriched formula was first shown to reduce growth in preterm infants. Since that time, very little new information has become available to confirm or refute the finding that high n-3 and low n-6 LCPUFA intake reduces growth in very low birth weight infants. ${ }^{24}$ However, it is likely that in this specific group of infants, the balance between n-3 and n-6 LCPUFAs is critical for growth, and it is prudent to minimize the decline of ARA status, which has been associated with reduced growth. Supplementation with n-3 and n-6 LCPUFAs has been shown to be safe and possibly even beneficial in preterm infants when growth $^{24,31}$ and body composition ${ }^{32}$ are used as the safety parameters.

\section{Supplementation with High Dosages of LCPUFAs.} The dosages of LCPUFAs used in early studies were chosen to produce the same concentrations of ARA and DHA in formula as seen in term breast milk. This might not be a wise approach for preterm infants, particularly for very and extremely preterm infants, whose requirements for LCPUFAs and other nutrients exceed what is normally provided in the small volumes that they are able to tolerate during the first days or weeks of life. Because the amount of DHA provided by ingesting breast milk is well below the in utero accretion rate, providing DHA at a dose higher than that of term human milk might better fulfill requirements and confer health benefits. Three studies report outcome data in preterm infants fed milk with a DHA content exceeding 0.2\%-0.4\% fatty acids, which are the levels most widely used in previous studies $^{33-37}$ (Table II).

One study examining the effect of providing DHA supplementation $(0.5 \%$ of total fatty acids) for up to 9 months after term reported that DHA improved growth in the entire cohort of preterm infants and improved mental development in boys. ${ }^{33}$ It should be noted that $\gamma$-linoleic acid, not ARA, was the n-6 PUFA source in the supplement used in that study.

In another study, the objective was to evaluate effects on neurologic development of supplementing human milk with oils (DSM, Heerlen, The Netherlands) that provided an extra $32 \mathrm{mg}$ of DHA and ARA per day. ${ }^{34}$ This intervention started 1 week after birth and continued until hospital discharge. Interestingly, DHA content of the control human milk was high $(0.7 \%$ total fatty acids), probably related to the high fish consumption of the mothers. Combined with the LCPUFAs in human milk, infants received $59 \mathrm{mg} / \mathrm{kg} /$ day of DHA and $48 \mathrm{mg} / \mathrm{kg} /$ day of ARA. At the 6-month follow-up evaluation, the intervention group performed better than the control group in the problem-solving subscore of the Ages and Stages Questionnaire. An electrophysiological assessment of event-related potentials revealed that infants in the intervention group also had significantly lower responses to a standard image, indicating better recognition memory. At 20 months postnatal age, no differences in the mental and motor development scores of the Ages and Stages Questionnaire or in the 
Table II. Visual acuity and development outcome results with DHA supplementation in preterm infants

\begin{tabular}{|c|c|c|c|c|c|c|c|}
\hline Reference & Site & $\begin{array}{l}\text { Age, } \\
\text { weeks }\end{array}$ & n & Groups & Duration & Age & Outcomes \\
\hline Fewtrell et al (2004) & $\begin{array}{l}\text { United } \\
\quad \text { Kingdom }\end{array}$ & $25-34$ & 238 & $\begin{array}{l}\text { DHA } 0.5 \%+\gamma \text {-LA versus } \\
\text { no LCPUFAs }\end{array}$ & $\begin{array}{l}\text { Up to } 9 \\
\text { months CA }\end{array}$ & 18 months $\mathrm{CA}$ & $\begin{array}{l}\text { No overall difference in Bayley } \\
\text { MDI and Psychomotor } \\
\text { Development Index; higher } \\
\text { Bayley MDI in boys }\end{array}$ \\
\hline Smithers et al (2008) & Australia & $27-31$ & 657 & $\begin{array}{l}\text { DHA } 1 \% \text { versus DHA } 0.30 \% \\
\text { (no difference in ARA) }\end{array}$ & $\begin{array}{l}\text { Days } 2-5 \text { until } \\
\text { due date }\end{array}$ & $\begin{array}{l}2 \text { and } 4 \\
\text { months } \mathrm{CA}\end{array}$ & $\begin{array}{l}\text { No difference in visual acuity } \\
\text { at } 2 \text { months; higher visual } \\
\text { acuity at } 4 \text { months }\end{array}$ \\
\hline Makrides et al $(2009)^{35}$ & & & & & & 18 months CA & $\begin{array}{l}\text { No overall difference in Bayley } \\
\text { MDI and Psychomotor } \\
\text { Development Index; fewer } \\
\text { severe mental delay; higher } \\
\text { MDI in girls; higher MDI } \\
\text { (unadjusted analysis only) } \\
\text { and fewer mild mental delay } \\
\text { in infants with birth weight } \\
<1250 \mathrm{~g}\end{array}$ \\
\hline Smithers et al $(2010)^{39}$ & & & & & & $\begin{array}{l}26 \text { months } \mathrm{CA} \text {; } \\
3-5 \text { years CA }\end{array}$ & $\begin{array}{l}\text { No difference in language } \\
\text { development; no difference } \\
\text { in behavior }\end{array}$ \\
\hline Henricksen et al $(2010)^{34}$ & Norway & & 141 & $\begin{array}{l}\text { DHA } 59 \mathrm{mg} / \mathrm{kg} / \text { day + ARA } \\
45 \mathrm{mg} / \mathrm{kg} / \text { day versus } \\
\text { DHA } 32 \mathrm{mg} / \mathrm{kg} / \text { day + ARA } \\
22 \mathrm{mg} / \mathrm{kg} / \text { day }\end{array}$ & $\begin{array}{r}1 \text { week until } \\
\text { discharge }\end{array}$ & 6 months CA & $\begin{array}{l}\text { Higher problem solving subscore } \\
\text { at the ages and stages } \\
\text { questionnaire; better } \\
\text { recognition memory at the } \\
\text { event-related potential test }\end{array}$ \\
\hline Westerberg et al $(2011)^{38}$ & & & & & & $\begin{array}{l}20 \text { months } \\
\text { postnatal age }\end{array}$ & $\begin{array}{l}\text { No difference in Bayley MDI, but } \\
\text { significant correlation between } \\
\text { plasma DHA concentration } \\
\text { at discharge and MDI; better } \\
\text { attention capacity at the } \\
\text { free-play session test }\end{array}$ \\
\hline
\end{tabular}

$C A$, corrected age.

Shown are results of visual acuity and development outcome assessments of randomized controlled trials using DHA supplementation in preterm infants at a dose exceeding $0.4 \%$ of total fatty acids. DHA and ARA are expressed as \% total fatty acids.

Mental Development Index (MDI) score of the Bayley Scales of Infant Development ${ }^{38}$ were observed; however, plasma DHA concentration at discharge was positively correlated with Bayley MDI score. The intervention group had better results at 20 months in the free-play sessions, suggesting positive effects from supplementation on functions related to attention. Furthermore, plasma DHA concentration at discharge was positively correlated with "sustained attention." ${ }^{38}$

The third study was designed to compare the effects of a high versus a standard DHA intake (ie, $1 \%$ vs $0.35 \%$ total fatty acids as DHA) with ARA intake kept constant. This study included breastfed and formula-fed infants. Mothers who provided breast milk took capsules containing $3 \mathrm{~g}$ of either tuna oil (900 mg DHA) or soy oil (no DHA), resulting in milk with either high or standard DHA content. A formula with matching high versus standard DHA concentrations was used for infants who required supplementary feeds. The feeding regimen was started between days 2 and 5 after birth and maintained until expected term. All infants received a standard term formula with DHA after the expected term. Visual acuity was significantly improved at 4 months corrected age in the high-DHA group. ${ }^{37}$ At 18 months there were no overall differences in the MDI or the Bayley Psychomotor Developmental Index, but fewer infants had an MDI score $<70 .{ }^{35}$ Infants who weighed $<1250 \mathrm{~g}$ and were fed the high-DHA diet had a higher MDI score than controls (mean difference, 4.6; 95\% CI, 0.1-9.0; $P<$ $.05)$, but the difference was not significant when gestational age at delivery, sex, maternal education, and birth order were taken into account. Girls fed a high-DHA diet had higher MDI scores and were less likely to have mild or significant developmental delay than control girls. This effect was not seen in boys. Finally, the early advantage in visual and cognitive functions did not translate into any clinically meaningful change in language development or behavior when assessed in early childhood. ${ }^{39}$

Giving very low birth weight infants larger doses of DHA appears to be safe and may provide further health benefits for functions beyond development. One trial found a reduced incidence of oxygen treatment at 36 weeks in the high-DHA group compared with the standard-DHA group ${ }^{35}$ which can be interpreted as a short-term benefit of high DHA doses.

Overall, the studies published to date indicate that greater DHA supplementation is associated with better neurologic outcomes. One study suggested that the smallest infants, which are the most vulnerable to DHA deficiency, are those the most likely to reap the greatest benefit from high-dose supplementation. ${ }^{35}$ The observation that a nonsignificant difference in mean MDI translates to fewer infants with a low MDI score suggests that low development score are at least in part, due to early nutritional deficiencies. 
Although DHA supplementation beyond discharge and/or expected term is recommended, ${ }^{40}$ one of the trials did not use such a strategy. ${ }^{35}$ This may explain, high-dose versus standard-dose DHA supplementation failed to significantly improve the development outcome of the whole cohort, particularly when the assessment was performed long after the period of supplementation. It also should be noted that none of the regimens studied prevented the early DHA deficit due to parenteral nutrition. ${ }^{41}$ This early DHA deficit during the parenteral nutrition phase may have contributed to the impaired development at 18 months of age.

\section{Assessment of Status and Current Practices}

\section{LCPUFA Composition: Human Milk}

The fat and fatty acid content of human milk is known to be highly variable. For example, fatty acid composition varies among countries, from woman-to-woman, by duration of gestation and stage of lactation, throughout the day, and during a feeding. This variability may be of little significance for a healthy term infant, but it presents more of a risk to the preterm infant, whose feedings are delivered artificially and controlled by a medical team.

The fatty acid composition of human milk is known to vary worldwide. Variability is greater for ALA and DHA than for LA and ARA. ${ }^{42,43}$ The LA content of human milk ranges from $7.9 \%$ in the Philippines to $17.8 \%$ in Chile, a $<2.5$-fold difference. ALA has a 5-fold disparity, ranging from $0.43 \%$ in the Philippines to $2 \%$ in China. The worldwide mean $( \pm \mathrm{SD})$ concentration of DHA in breast milk (by weight) is $0.32 \% \pm 0.22 \%$ (range, $0.06 \%-1.4 \%$ ), and that of ARA is $0.47 \% \pm 0.13 \%$ (range, $0.24 \%-1 \%$ ). ${ }^{44}$ Mothers who live in coastal areas or on islands produce milk with the highest DHA levels. Mothers who live away from the coast and/or in developed countries consume fewer marine foods and produce milk relatively low in DHA. Human milk responds to changes in the maternal diet, and LCPUFA supplementation increases DHA concentration in milk.

Fatty acid composition of human milk varies by stage of lactation and duration of gestation. Total fat, LA, and ALA increase and DHA and ARA decrease as milk transitions from colostrum to mature milk. There are no important differences between full-term and preterm human milk in terms of total fat, most saturated and monounsaturated fatty acids, or the EFAs LA and ALA. ${ }^{45}$ Preterm milk may contain a slightly higher proportion of medium- and intermediatechain fatty acids than term milk, which may be advantageous for fat and calcium absorption in preterm infants. Compositional differences in LCPUFA levels between term and preterm milk are of interest. As in full-term milk, concentrations of both DHA and ARA in preterm milk decrease over the first 3-5 weeks of lactation. Some studies have reported more ARA and/or DHA in preterm milk than in full-term milk, whereas other studies have reported the opposite. ${ }^{45}$ In terms of percent contribution to total fatty acids, however, DHA is often higher in preterm milk than in fullterm milk. ${ }^{45}$

The reported ranges of DHA and ARA values in preterm human milk are summarized in Table III. Based on the values presented in Table III, the estimated mean $( \pm \mathrm{SD})$ concentration of DHA in preterm human milk (by weight) is $0.33 \% \pm 0.10 \%$ (range, $0.22 \%-0.55 \%$ ), and that of ARA is $0.55 \% \pm 0.09 \%$ (range, $0.44 \%-0.69 \%$ ). These values are very similar to those reported in full-term human milk. ${ }^{44}$

Banked human milk may be fed to preterm infants when their mothers' own milk is unavailable or insufficient. The estimated mean fat content in banked human milk is $3.2 \mathrm{~g} / 100$ $\mathrm{mL}$, somewhat lower than the generally accepted value for mature human milk. ${ }^{46,47}$ This may be related to inadequate emptying of the breast during pumping. The LCPUFA content of banked human milk appears to be similar to that of mature milk. Pasteurization and storage of banked human milk induces lipolysis, inactivates bile salt-stimulated lipase and lipoprotein lipase, reduces fats, and increases the absolute amount of free fatty acids in pooled samples. These effects alter the integrity of human milk and may contribute to slower growth in preterm infants fed banked milk versus their mothers' own milk. ${ }^{7}$

\section{LCPUFA Composition: Infant Formula Products}

Commercial infant formulas marketed for preterm infants vary in fat quantity and quality. Total fat ranges between

Table III. Composition of LCPUFA in milk from mothers of preterm infants

\begin{tabular}{|c|c|c|c|c|c|c|}
\hline \multirow[b]{2}{*}{ Reference } & \multirow[b]{2}{*}{ Site } & \multirow[b]{2}{*}{ Age, weeks } & \multirow[b]{2}{*}{$\mathbf{n}$} & \multicolumn{2}{|c|}{$\%$ total fatty acids } & \multirow[b]{2}{*}{ Sampling time point(s) } \\
\hline & & & & DHA & ARA & \\
\hline Smithers et al (2008) ${ }^{36}$ & Australia & $<33$ & 21 & 0.26 & 0.45 & Pooled; $26-40$ weeks \\
\hline Clandinin et al $(1997)^{54}$ & Canada & $28-34$ & 25 & 0.3 & 0.54 & $<42$ days of life \\
\hline Jacobs et al $(1996)^{55}$ & Netherlands & $30-35$ & 5 & 0.4 & 0.6 & Third week of life \\
\hline Carnielli et al (1998) ${ }^{9}$ & Netherlands & $27-33$ & 20 & 0.26 & 0.48 & 28 days of life \\
\hline Beijers and Schaafsma (1996) ${ }^{56}$ & Netherlands & $26-36$ & 65 & 0.32 & 0.49 & $\begin{array}{l}\text { Mean colostrum, } 1 \text { week; transitional, } \\
2 \text { weeks; mature, >2 weeks }\end{array}$ \\
\hline Bitman et al $(1983)^{57}$ & US & $26-36$ & 46 & 0.22 & 0.56 & 42 days of life \\
\hline${\text { Luukkainen et al }(1995)^{58}}^{58}$ & Finland & $25-33$ & 23 & 0.4 & 0.44 & Mean, 5 samplings over 3 months \\
\hline Genzel-Boroviczény et al $(1997)^{59}$ & Germany & $24-33$ & 19 & 0.32 & 0.59 & Mean, 4 samplings over 1 month \\
\hline Rueda et al $(1998)^{60}$ & Spain & $33-36$ & 6 & 0.55 & 0.69 & $\begin{array}{l}\text { Mean colostrum, } 1 \text { week; transitional, } \\
2 \text { weeks; mature, >2 weeks }\end{array}$ \\
\hline Kovács et al $(2005)^{61}$ & Hungary & $23-33$ & 8 & 0.27 & 0.66 & Mean, 5 samplings over 3 weeks \\
\hline
\end{tabular}


3.8 and $4.2 \mathrm{~g} / \mathrm{dL}$, provided by a combination of long-chain triglycerides and MCTs. Up to $40 \%-50 \%$ of total fat may come from MCTs. Preterm infant formula is routinely supplemented with commercially available sources of LCPUFA, so that the fatty acid composition resembles that of human milk. Most of the LCPUFA oils added to infant formulas are derived from microorganisms; however, some are derived from a combination of low-EPA fish oil as a source of DHA and oil from microorganisms as a source of ARA.

\section{LCPUFA Intake from Infant Feedings}

The estimated DHA accretion rate is $45 \mathrm{mg} / \mathrm{kg} /$ day during the last trimester of gestation. ${ }^{3}$ Most contemporary intravenous lipid emulsions provide little if any LCPUFAs. Human milk and formulas designed for preterm infants contain DHA and ARA, but arguably in insufficient amounts to compensate for an accumulated deficit. Consequently, preterm infants who receive many weeks of parenteral nutrition followed by human milk and/or commercial preterm formula may accumulate a DHA deficit of up to $50 \%$ of the normal rate. ${ }^{41}$ Table IV compares DHA and ARA intakes from selected enteral feedings given to preterm infants. Assuming an average fat content of $3.9 \mathrm{~g} \mathrm{fat} / \mathrm{dL}$ in human milk, milk with $0.2 \%$ $0.4 \%$ fatty acids as DHA would provide a $1-\mathrm{kg}$ preterm infant fed at full enteral feeds of $180 \mathrm{~mL} /$ day with only 14$28 \mathrm{mg} \mathrm{DHA} / \mathrm{kg} /$ day, an amount clearly below the in utero accretion rate of $45 \mathrm{mg} / \mathrm{kg} /$ day.

\section{LCPUFA Status: Insights from Studies with High Doses of DHA}

The effect of milk DHA on preterm infant plasma or erythrocyte DHA depends largely on dose. ${ }^{36}$ Milk that contains $\sim 0.8 \%$ DHA provides an intake of $45 \mathrm{mg} / \mathrm{kg} /$ day, assuming a human milk fat content of $3.7 \%$ and a volume intake of $150 \mathrm{~mL} / \mathrm{kg} /$ day. In the study by Smithers et al, ${ }^{36}$ milk DHA content ranged from $0.2 \%$ to $1.25 \%$ of total fatty acids (assumed to represent 11-67 mg/kg/day), and there was a di- rect relationship between milk DHA content and erythrocyte DHA content. At a milk DHA content of $>0.8 \%$ of fatty acids ( $\sim 45 \mathrm{mg} / \mathrm{kg} / \mathrm{day})$, none of the infants had an erythrocyte DHA concentration $<6 \%$ at expected term, but at a milk DHA content of $1 \%(\sim 54 \mathrm{mg} / \mathrm{kg} /$ day $)$, the erythrocyte DHA concentration ranged between $6.5 \%$ and $9 \%$, within the range expected in term infants at birth. ${ }^{2,3}$ The DHA intake of the control infants (ie, $32 \mathrm{mg} / \mathrm{kg} /$ day) in the study of Henriksen et $\mathrm{al}^{34}$ did not prevent a decline in plasma DHA concentrations, confirming that intake below the fetal accretion rate is inadequate to maintain normal DHA status in preterm infants. ${ }^{34}$ In the intervention group of the same study, preterm infants received $59 \mathrm{mg}$ DHA/ $/ \mathrm{kg} /$ day, which increased plasma DHA concentration by $12 \%$ from the time of study inclusion to hospital discharge. Assuming a DHA intestinal absorption rate of $80 \%$, DHA intake between $\sim 55$ and $60 \mathrm{mg} / \mathrm{kg} /$ day provides DHA at a rate matching the fetal accretion rate.

In terms of ARA intake, the aforementioned studies differed greatly. In one study, ARA supplementation was given at a dose similar to that of DHA, ${ }^{34}$ whereas in another study no ARA supplementation was given. ${ }^{36}$ Consequently, changes in ARA status during the DHA supplementation period differed between these studies. A dramatic decline in ARA status was observed when milk ARA content was $\sim 0.5 \%$ of total fatty acids ${ }^{36}$; in contrast, ARA status was stable when similar doses of ARA and DHA were used. ${ }^{34}$ Additional studies are needed to determine the potential effects of these changes on ARA status, but because no decrease in ARA status is observed during fetal life, such biological effects in preterm infants probably should be avoided. Because the DHA:ARA ratio varies widely in term milk ${ }^{44}$ and preterm milk, ${ }^{48}$ future research should focus on defining individual DHA and ARA needs rather than an optimal DHA:ARA ratio.

Finally, the studies cited here provide clues on how to increase LCPUFA intake in human milk-fed preterm

Table IV. Estimated LCPUFA intake at $120 \mathrm{kcal} / \mathrm{kg} /$ day from various forms of human milk and preterm infant formulas ${ }^{\star}$

\begin{tabular}{|c|c|c|c|c|c|c|c|c|c|}
\hline & \multirow[b]{2}{*}{ Total fat, $\mathrm{g} / 100 \mathrm{~mL}$} & \multicolumn{2}{|c|}{ LCPUFA, \% total fatty acids } & \multicolumn{2}{|c|}{ LCPUFA, mg/100 mL } & \multicolumn{2}{|c|}{ LCPUFA intake, mg/kg/day } & \multicolumn{2}{|c|}{ LCPUFA absorbed, $\mathrm{mg} / \mathrm{kg} / \mathrm{day}^{\dagger}$} \\
\hline & & DHA & ARA & DHA & ARA & DHA & ARA & DHA & ARA \\
\hline \multicolumn{10}{|l|}{ Human milk } \\
\hline Full-term & $4.2^{\ddagger}$ & $0.32^{\S}$ & $0.47^{\S}$ & 13.4 & 19.7 & 24.2 & 35.5 & 19 & 28 \\
\hline Preterm & $3.9^{\ddagger}$ & $0.33^{\mathbb{\pi}}$ & $0.55^{\S}$ & 12.9 & 21.4 & 23.2 & 38.6 & 18 & 31 \\
\hline Banked & $3.2^{\star \star}$ & $0.32^{\dagger \dagger}$ & $0.47^{\dagger \dagger}$ & 10.2 & 15.0 & 18.4 & 27.1 & 15 & 22 \\
\hline Fortified & $4.4^{\ddagger \ddagger}$ & $0.33^{\S \S}$ & $0.55^{\S \S}$ & 12.9 & 21.4 & 19.3 & 32.2 & 15 & 26 \\
\hline \multicolumn{10}{|l|}{ Formula } \\
\hline Standard & 3.6 & 0.24 & 0.52 & 8.6 & 18.7 & 15.6 & 33.7 & 12 & 27 \\
\hline Preterm & 4.2 & 0.3 & 0.55 & 12.6 & 23.1 & 18.9 & 34.6 & 15 & 28 \\
\hline
\end{tabular}

*Full-term, preterm, and banked human milk and standard formula assume $20 \mathrm{kcal} / 0 \mathrm{z}$ and $180 \mathrm{~mL} / \mathrm{kg} /$ day; fortified and preterm formula assume $24 \mathrm{kcal} / \mathrm{oz}$ and $150 \mathrm{~mL} / \mathrm{kg} / \mathrm{day}$. †Intestinal absorption, $80 \% .^{9}$

tData from Lawrence (1995). ${ }^{62}$

¿Data from Brenna et al (2007). ${ }^{44}$

qSee Table I.

**Data from Wojcik et al (2009). ${ }^{46}$

††Assuming fatty acid concentrations of full-term milk. ${ }^{63}$

$\ddagger$ Assuming the fat content of preterm milk ${ }^{62}$ plus $0.5 \mathrm{~g}$ fat $/ 100 \mathrm{~mL}$ from non-LCPUFA-containing fortifier

$\S \S$ Assuming fatty acid concentrations of preterm milk.

ๆฯMean of preterm formula products available in the US. 
infants. In one study, fish oil was given to lactating mothers to increase the DHA content of their milk. Supplementing mothers with the appropriate amount of tuna oil increased human milk DHA concentrations to the desired level with only a small increase in EPA and no change in ARA levels. ${ }^{48}$ However, despite its physiological basis, this strategy leads to large variations in the DHA content of human milk, with values as low as $0.3 \%$ and as high as $2.5 \%$ observed. Furthermore, this strategy does not allow supplementation with both ARA and DHA concomitantly. Adding DHA with or without ARA directly into the feeding is likely to be the most reliable technique for delivering adequate amounts of DHA to preterm infants.

\section{Previous LCPUFA Recommendations}

Various regulatory bodies, professional organizations, and expert panels have issued recommendations and consensus statements on LCPUFA intake for preterm infants. These recommendations rely on the composition of human milk and the results of decades of research related to LCPUFA intake and blood and tissue levels, anthropometric parameters, and visual and neurocognitive outcomes. Evidence supports the superiority of human milk and the safety of supplementing formulas with DHA and ARA in amounts similar to those found in human milk. ${ }^{49}$

Table V summarizes Previous recommendations. Interestingly, in 2002 the Expert Panel of the Life Sciences Research Organization did not recognize a need for LCPUFAs and did not recommend a minimum content of ARA, DHA, or EPA for preterm infant formulas at that time. Just 3 years later, Koletzko and Innis ${ }^{1}$ recognized the "essentiality" of ARA and DHA and proposed a minimum value for the requirements of preterm infants. More recently, the European Society for Pediatric Gastroenterology, Hepatology, and Nutrition did not change the recommendations, but rather expressed them as $\mathrm{mg} / \mathrm{kg} / \mathrm{day}$ instead of percentage of total fatty acids. ${ }^{50}$

\section{Updated Recommendations for LCPUFA Intake in Preterm Infants}

\section{Breastfeeding}

In agreement with other reports, we strongly endorse human milk as the preferred food source for preterm infants. We emphasize, however, that fortifiers and supplements must be used appropriately to meet the specific needs of preterm infants, especially very preterm infants. The DHA content in human milk is highly variable, mainly because of variations of maternal diets. Nutritional counseling during the lactation period is recommended to ensure optimal mother's intake of omega-3 fatty acids.

\section{Fat, EFA, and MCT Intake}

There are no new data since the recommendations of 2010 to modify the recommendations for total fat intake, EFAs, and MCTs for preterm infants. ${ }^{1}$

\section{DHA}

Given the limited and highly variable formation of DHA from ALA, and the critical role of DHA in normal retinal and brain development in humans, DHA should be considered conditionally essential during early development. Early deprivation of DHA should be identified early and treated aggressively, because it is not known definitively if

\begin{tabular}{|c|c|c|c|c|}
\hline & $\begin{array}{l}\text { Life Sciences Research } \\
\text { Organization, 2002* }\end{array}$ & Koletzko and Innis, $2005^{\dagger}$ & $\begin{array}{c}\text { European Society for Pediatric Gastroenterology, } \\
\text { Hepatology, and Nutrition, 2010 }\end{array}$ & Current \\
\hline \multicolumn{5}{|l|}{ LA (C18:3n-3) } \\
\hline$\%$ total energy & - & $3.2-12.8$ & $3.2-12.8$ & $3.2-12.8$ \\
\hline $\mathrm{mg} / 100 \mathrm{kcal}$ & $352-1425$ & $352-1425$ & $350-1400$ & $350-1400$ \\
\hline $\mathrm{mg} / \mathrm{kg} / \mathrm{day}$ & - & $600-1680$ & $385-1540$ & $385-1540$ \\
\hline$\%$ total fatty acids & $8-25$ & $8-25$ & - & - \\
\hline \multicolumn{5}{|l|}{ ALA $(C 18: 2 n-6)$} \\
\hline \% total energy & - & $0.7-2.1$ & $\geq 0.45$ & $\geq 0.45$ \\
\hline $\mathrm{mg} / 100 \mathrm{kcal}$ & $77-228$ & $77-228$ & $\geq 50$ & $\geq 50$ \\
\hline $\mathrm{mg} / \mathrm{kg} / \mathrm{day}$ & - & - & $\geq 55$ & $\geq 55$ \\
\hline$\%$ total fatty acids & $1.75-4$ & $1.75-4$ & $\geq 0.9$ & $\geq 0.9$ \\
\hline LA:ALA & $6-16: 1$ & 6-16:1 & $5-15: 1$ & $5-15: 1$ \\
\hline \multicolumn{5}{|l|}{ ARA (C20:4n-6) } \\
\hline mg/100 kcal & - & - & $16-39$ & - \\
\hline mg/kg/day & - & - & $18-42$ & $18-45$ \\
\hline$\%$ total fatty acids & $\leq 0.6$ & $0.3-0.7$ & - & - \\
\hline \multicolumn{5}{|l|}{ DHA (C22:6n-3) } \\
\hline $\mathrm{mg} / 100 \mathrm{kcal}$ & - & - & $11-27$ & - \\
\hline $\mathrm{mg} / \mathrm{kg} / \mathrm{day}$ & - & - & $12-30$ & $12-60$ \\
\hline \% total fatty acids & $\leq 0.35$ & $0.2-0.5$ & - & - \\
\hline ARA:DHA & $1.5-2: 1$ & $1.2-2: 1$ & $1-2: 1$ & - \\
\hline EPA (C20:5n-3) & $\leq 30 \% \mathrm{DHA}$ & $\leq 30 \% \mathrm{DHA}$ & $\leq 30 \% \mathrm{DHA}$ & $\leq 20 \mathrm{mg} / \mathrm{kg} /$ day \\
\hline
\end{tabular}

*Klein (2002). ${ }^{64}$ 
a transient deficit can be compensated for with regard to central nervous system growth and maturation. We emphasize that current nutritional management does not provide sufficient amounts of preformed DHA during the parenteral and enteral nutrition periods and in very preterm/ very low birth weight infants until the due date. Nutrient recommendations should be expressed as absolute amount per $\mathrm{kg} /$ day rather than as a proportion of total fatty acids, because the latter applies only if full enteral feeding is reached. The fetal accretion rate of DHA is approximately $45 \mathrm{mg} / \mathrm{kg} /$ day. Greater amounts may be needed to compensate for intestinal malabsorption, DHA oxidation, and early deficit. On the other hand, the amount of DHA that can be synthesized endogenously by preterm infants is unclear. DHA intakes of $55-60 \mathrm{mg} / \mathrm{kg} /$ day from the time of preterm birth to expected term have been tested and appear to be safe, to promote normal DHA status, and to improve visual and neurocognitive functions. These values are likely to represent an adequate intake for very preterm infants, but further research is needed to confirm that they represent adequate intake for all infant groups (ie, extremely, very, and moderately preterm infants, with or without intrauterine growth restriction, and males and females). Because the maximum DHA content of human milk is $>1.5 \%$ of fatty acids (equivalent to $84 \mathrm{mg} / \mathrm{kg} /$ day), ${ }^{51}$ and because no studies with such a high intake in preterm infants have been reported, no upper limit can be set with certainty.

\section{ARA}

Preformed ARA should be provided to ensure adequate ARA levels during the period of DHA supplementation. Limited data are available to define the necessary ARA dose with certainty. When a high dose of DHA is provided, $45 \mathrm{mg} / \mathrm{kg} /$ day of ARA has been shown to support growth and normal ARA status.

\section{EPA}

Limited data are available to identify whether there is any benefit to including EPA in the diet of preterm infants. Thus, we recommend an EPA intake not exceeding $20 \mathrm{mg} /$ $\mathrm{kg} /$ day, which is the mean $+1 \mathrm{SD}$ amount of EPA provided daily by human milk when fed at $180 \mathrm{ml} / \mathrm{kg} /$ day. ${ }^{48}$

\section{Duration of Supplementation}

The recommendations for DHA, ARA, and EPA specified above should be continued until the infant reaches the expected due date. After the expected due date, recommendations for term infants should be applied. ${ }^{52}$ Research is needed to examine whether LCPUFA supplementation after the due date may provide additional benefits.

\section{Gaps in Knowledge and Recommendations for Future Research}

Future research should consider short- and long-term effects of LCPUFA status of preterm infants before and after the due date according to interindividual differences, such as genetic variations in fatty acid desaturase activities or sex. Investigators are encouraged to address subgroups that have specific needs and benefits, such as extremely preterm infants and preterm infants with intrauterine growth retardation, extrauterine growth retardation, bronchopulmonary dysplasia, or prolonged parenteral nutrition. Supplementation studies should be designed to examine growth, body composition, visual and cognitive development, attention and behavioral disorders, and effects on immune outcomes and cardiovascular function. Studies evaluating the effects of different amounts of LCPUFAs and the specific effects of ARA supply, with sufficient duration of intake, adequate sample sizes, and standardized methodology for outcome measurements, warrant careful consideration. Future studies should evaluate various DHA levels to define dose-response relationships and elucidate potential immediate and long-term benefits and safety issues. The most effective mode of delivering LCPUFAs (ie, through supplementation of the mother, supplements mixed in milk, and/or enriched fortifiers) also merit further evaluation.

We thank Mrs Gretchen Duenas and the Association pour la Recherche et la Formation en Néonatologie (ARFEN) for providing technical assistance and Professors Jean-Charles Picaud, $M D, P h D$, and Bernard Salle, MD, for providing additional balance study data.

\section{Author Disclosures}

Ricardo Uauy, MD, PhD, chaired the Symposium on Nutrition of the Preterm Infant. Mead Johnson Nutrition paid his travel expenses and provided an honorarium for contributing to, organizing, and chairing the meeting and for his assisting with the final editing of the supplement. All authors received honoraria from Mead Johnson Nutrition for attendance, presentation, and manuscript preparation. A. L. wrote the first draft of this manuscript.

Reprint requests: Alexandre Lapillonne, MD, PhD, Professor of Pediatrics, Department of Neonatology, Necker Hospital, 149 rue de Sevres, 75015 Paris, France. E-mail: alexandre.lapillonne@nck.aphp.fr.

\section{References}

1. Koletzko B, Innis SM. Lipids. In: Tsang RC, Uauy R, Koletzko B, Zlotkin SH, eds. Nutrition of the preterm infant: scientific basis and practical guidelines. Cincinnati $(\mathrm{OH})$ : Digital Educational Publishing; 2005. p. 97-140.

2. Innis SM. Essential fatty acid transfer and fetal development. Placenta 2005;26(Suppl A):S70-5.

3. Lapillonne A, Jensen CL. Reevaluation of the DHA requirement for the premature infant. Prostaglandins Leukot Essent Fatty Acids 2009;81: 143-50.

4. Haggarty P. Effect of placental function on fatty acid requirements during pregnancy. Eur J Clin Nutr 2004;58:1559-70.

5. Uauy R, Mena P, Wegher B, Nieto S, Salem N Jr. Long-chain polyunsaturated fatty acid formation in neonates: effect of gestational age and intrauterine growth. Pediatr Res 2000;47:127-35. 
6. Straarup EM, Lauritzen L, Faerk J, Høy CE, Michaelsen KF. The stereospecific triacylglycerol structures and fatty acid profiles of human milk and infant formulas. J Pediatr Gastroenterol Nutr 2006;42:293-9.

7. Andersson Y, Sävman K, Bläckberg L, Hernell O. Pasteurization of mother's own milk reduces fat absorption and growth in preterm infants. Acta Paediatr 2007;96:1445-9.

8. Montjaux N, Hascoet JM, Lapillonne A, Kermorvant-Duchemin E, Simeoni U, Saliba E, et al. A prospective, randomized, double-blind crossover study comparing rhBSSL (recombinant human bile salt stimulated lipase) and placebo added to pasteurized breast milk in preterm infants. PAS/ASPR meeting, Denver April 30-May 3 2011. Abstract 2855.7.

9. Carnielli VP, Verlato G, Pederzini F, Luijendijk I, Boerlage A, Pedrotti D, et al. Intestinal absorption of long-chain polyunsaturated fatty acids in preterm infants fed breast milk or formula. Am J Clin Nutr 1998;67: 97-103.

10. Chirouze V, Lapillonne A, Putet G, Salle BL. Red blood cell fatty acid composition in low-birth-weight infants fed either human milk or formula during the first months of life. Acta Paediatr Suppl 1994;405:70-7.

11. Picq M, Chen P, Perez M, Michaud M, Véricel E, Guichardant M, et al. DHA metabolism: targeting the brain and lipoxygenatio. Mol Neurobiol 2010;42:48-51.

12. Carnielli VP, Simonato M, Verlato G, Luijendijk I, De Curtis M, Sauer PJ, et al. Synthesis of long-chain polyunsaturated fatty acids in preterm newborns fed formula with long-chain polyunsaturated fatty acids. Am J Clin Nutr 2007;86:1323-30.

13. Schaeffer L, Gohlke H, Müller M, Heid IM, Palmer LJ, Kompauer I, et al. Common genetic variants of the FADS1 FADS2 gene cluster and their reconstructed haplotypes are associated with the fatty acid composition in phospholipids. Hum Mol Genet 2006;15:1745-56.

14. Lattka E, Illig T, Heinrich J, Koletzko B. Do FADS genotypes enhance our knowledge about fatty acid related phenotypes? Clin Nutr 2010;29: 277-87.

15. Lattka E, Illig T, Koletzko B, Heinrich J. Genetic variants of the FADS1 FADS2 gene cluster as related to essential fatty acid metabolism. Curr Opin Lipidol 2010;21:64-9.

16. Lin YH, Llanos A, Mena P, Uauy R, Salem N Jr, Pawlosky RJ. Compartmental analyses of $2 \mathrm{H} 5$ - $\alpha$-linolenic acid and $\mathrm{C}$ - $\mathrm{U}$-eicosapentaenoic acid toward synthesis of plasma-labeled 22:6n-3 in newborn term infants. Am J Clin Nutr 2010;92:284-93.

17. Pawlosky RJ, Lin YH, Llanos A, Mena P, Uauy R, Salem NJ. Compartmental analyses of plasma $13 \mathrm{C}$ - and $2 \mathrm{H}$-labeled $\mathrm{n}-6$ fatty acids arising from oral administrations of $13 \mathrm{C}-\mathrm{U}-18: 2 \mathrm{n}-6$ and $2 \mathrm{H} 5-20: 3 \mathrm{n}-6$ in newborn infants. Pediatr Res 2006;60:327-33.

18. Plourde M, Chouinard-Watkins R, Vandal M, Zhang Y, Lawrence P, Brenna JT, et al. Plasma incorporation, apparent retroconversion and $\beta$-oxidation of $13 \mathrm{C}$-docosahexaenoic acid in the elderly. Nutr Metab (Lond) 2011;8:5.

19. D’Ascenzo R, D’Egidio S, Angelini L, Bellagamba MP, Manna M, Pompilio A, et al. Parenteral nutrition of preterm infants with a lipid emulsion containing $10 \%$ fish oil: effect on plasma lipids and longchain polyunsaturated fatty acids. J Pediatr 2011;159:33-8.

20. Innis SM. Dietary (n-3) fatty acids and brain development. J Nutr 2007; 137:855-9.

21. McCann JC, Ames BN. Is docosahexaenoic acid, an n-3 long-chain polyunsaturated fatty acid, required for development of normal brain function? An overview of evidence from cognitive and behavioral tests in humans and animals. Am J Clin Nutr 2005;82:281-95.

22. San Giovanni JP, Parra-Cabrera S, Colditz GA, Berkey CS, Dwyer JT. Meta-analysis of dietary essential fatty acids and long-chain polyunsaturated fatty acids as they relate to visual resolution acuity in healthy preterm infants. Pediatrics 2000;105:1292-8.

23. Uauy R, Hoffman DR, Mena P, Llanos A, Birch EE. Term infant studies of DHA and ARA supplementation on neurodevelopment: results of randomized controlled trials. J Pediatr 2003;143:S17-25.

24. Schulzke SM, Patole SK, Simmer K. Long-chain polyunsaturated fatty acid supplementation in preterm infants. Cochrane Database Syst Rev 2011;CD000375.
25. Georgieff MK, Innis SM. Controversial nutrients that potentially affect preterm neurodevelopment: essential fatty acids and iron. Pediatr Res 2005;57:99R-103R.

26. Heird WC, Lapillonne A. The role of essential fatty acids in development. Annu Rev Nutr 2005;25:549-71.

27. Fleith M, Clandinin MT. Dietary PUFA for preterm and term infants: review of clinical studies. Crit Rev Food Sci Nutr 2005;45:205-29.

28. Uauy R, Dangour AD. Fat and fatty acid requirements and recommendations for infants of 0-2 years and children of 2-18 years. Ann Nutr Metab 2009;55:76-96.

29. Koletzko B, Lien E, Agostoni C, Böhles H, Campoy C, Cetin I, et al. The roles of long-chain polyunsaturated fatty acids in pregnancy, lactation and infancy: review of current knowledge and consensus recommendations. J Perinat Med 2008;36:5-14.

30. Smithers LG, Gibson RA, McPhee A, Makrides M. Effect of long-chain polyunsaturated fatty acid supplementation of preterm infants on disease risk and neurodevelopment: a systematic review of randomized controlled trials. Am J Clin Nutr 2008;87:912-20.

31. Clandinin MT, Van Aerde JE, Merkel KL, Harris CL, Springer MA, Hansen JW, et al. Growth and development of preterm infants fed infant formulas containing docosahexaenoic acid and arachidonic acid. J Pediatr 2005;146:461-8.

32. Groh-Wargo S, Jacobs J, Auestad N, O'Connor DL, Moore JJ, Lerner E. Body composition in preterm infants who are fed long-chain polyunsaturated fatty acids: a prospective, randomized, controlled trial. Pediatr Res 2005;57:712-8.

33. Fewtrell MS, Abbott RA, Kennedy K, Singhal A, Morley R, Caine E, et al. Randomized, double-blind trial of long-chain polyunsaturated fatty acid supplementation with fish oil and borage oil in preterm infants. J Pediatr 2004;144:471-9.

34. Henriksen C, Haugholt $\mathrm{K}$, Lindgren $\mathrm{M}$, Aurvåg AK, Rønnestad A, Grønn M, et al. Improved cognitive development among preterm infants attributable to early supplementation of human milk with docosahexaenoic acid and arachidonic acid. Pediatrics 2008;121:1137-45.

35. Makrides M, Gibson RA, McPhee AJ, Collins CT, Davis PG, Doyle LW, et al. Neurodevelopmental outcomes of preterm infants fed high-dose docosahexaenoic acid: a randomized controlled trial. JAMA 2009;301: 175-82.

36. Smithers LG, Gibson RA, McPhee A, Makrides M. Effect of two doses of docosahexaenoic acid (DHA) in the diet of preterm infants on infant fatty acid status: results from the DINO trial. Prostaglandins Leukot Essent Fatty Acids 2008;79:141-6.

37. Smithers LG, Gibson RA, McPhee A, Makrides M. Higher dose of docosahexaenoic acid in the neonatal period improves visual acuity of preterm infants: results of a randomized controlled trial. Am J Clin Nutr 2008;88:1049-56

38. Westerberg AC, Schei R, Henriksen C, Smith L, Veierød MB, Drevon CA, et al. Attention among very low birth weight infants following early supplementation with docosahexaenoic and arachidonic acid. Acta Paediatr 2011;100:47-52.

39. Smithers LG, Collins CT, Simmonds LA, Gibson RA, McPhee A, Makrides M. Feeding preterm infants milk with a higher dose of docosahexaenoic acid than that used in current practice does not influence language or behavior in early childhood: a follow-up study of a randomized controlled trial. Am J Clin Nutr 2010;91:628-34.

40. Aggett PJ, Agostoni C, Axelsson I, De Curtis M, Goulet O, et al., ESPGHAN Committee on Nutrition. Feeding preterm infants after hospital discharge: a commentary by the ESPGHAN Committee on Nutrition. J Pediatr Gastroenterol Nutr 2006;42:596-603.

41. Lapillonne A, Eleni dit Trolli S, Kermorvant-Duchemin E. Postnatal docosahexaenoic acid deficiency is an inevitable consequence of current recommendations and practice in preterm infants. Neonatology 2010; 98:397-403.

42. Brenna JT, Lapillonne A. Background paper on fat and fatty acid requirements during pregnancy and lactation. Ann Nutr Metab 2009;55: 97-122.

43. Yuhas R, Pramuk K, Lien EL. Human milk fatty acid composition from nine countries varies most in DHA. Lipids 2006;41:851-8. 
44. Brenna JT, Varamini B, Jensen RG, Diersen-Schade DA, Boettcher JA, Arterburn LM. Docosahexaenoic and arachidonic acid concentrations in human breast milk worldwide. Am J Clin Nutr 2007;85:1457-64.

45. Bokor S, Koletzko B, Decsi T. Systematic review of fatty acid composition of human milk from mothers of preterm compared to full-term infants. Ann Nutr Metab 2007;51:550-6.

46. Wojcik KY, Rechtman DJ, Lee ML, Montoya A, Medo ET. Macronutrient analysis of a nationwide sample of donor breast milk. J Am Diet Assoc 2009;109:137-40.

47. Saarela T, Kokkonen J, Koivisto M. Macronutrient and energy contents of human milk fractions during the first six months of lactation. Acta Paediatr 2005;94:1176-81.

48. Smithers LG, Markrides M, Gibson RA. Human milk fatty acids from lactating mothers of preterm infants: a study revealing wide intra- and inter-individual variation. Prostaglandins Leukot Essent Fatty Acids 2010;83:9-13.

49. American Acedemy of Pediatrics, Committee on Nutrition. Pediatric nutrition handbook. 6th ed. Elk Grove Village (IL): American Academy of Pediatrics; 2009.

50. Agostoni C, Buonocore G, Carnielli VP, De Curtis M, Darmaun D, Decsi T, et al. Enteral nutrient supply for preterm infants: commentary from the European Society of Paediatric Gastroenterology, Hepatology and Nutrition Committee on Nutrition. J Pediatr Gastroenterol Nutr 2010;50:85-91.

51. Jensen RG. Lipids in human milk. Lipids 1999;34:1243-71.

52. Food and Agriculture Organization of the United Nations. Fat and fatty acids in human nutrition: report of an expert consultation. Available from: http:// foris.fao.org/preview/25553-0ece4cb94ac52f9a25af77ca5cfba7a8c.pdf. Accessed 2010.

53. Lapillonne A, Picaud JC, Chirouze V, Goudable J, Reygrobellet B, Claris O, et al. The use of low-EPA fish oil for long-chain polyunsaturated fatty acid supplementation of preterm infants. Pediatr Res 2000;48:835-41.

54. Clandinin MT, Van Aerde JE, Parrott A, Field CJ, Euler AR, Lien EL. Assessment of the efficacious dose of arachidonic and docosahexaenoic acids in preterm infant formulas: fatty acid composition of erythrocyte membrane lipids. Pediatr Res 1997;42:819-25.

55. Jacobs NJ, van Zoeren-Grobben D, Drejer GF, Bindels JG, Berger HM. Influence of long chain unsaturated fatty acids in formula feeds on lipid peroxidation and antioxidants in preterm infants. Pediatr Res 1996;40: 680-6.

56. Beijers RJ, Schaafsma A. Long-chain polyunsaturated fatty acid content in Dutch preterm breast milk; differences in the concentrations of docosahexaenoic acid and arachidonic acid due to length of gestation. Early Hum Dev 1996;44:215-23.

57. Bitman J, Wood L, Hamosh M, Hamosh P, Mehta NR. Comparison of the lipid composition of breast milk from mothers of term and preterm infants. Am J Clin Nutr 1983;38:300-12.

58. Luukkainen P, Salo MK, Nikkari T. The fatty acid composition of banked human milk and infant formulas: the choices of milk for feeding preterm infants. Eur J Pediatr 1995;154:316-9.

59. Genzel-Boroviczény O, Wahle J, Koletzko B. Fatty acid composition of human milk during the 1st month after term and preterm delivery. Eur J Pediatr 1997;156:142-7.

60. Rueda R, Ramírez M, García-Salmerón JL, Maldonado J, Gil A. Gestational age and origin of human milk influence total lipid and fatty acid contents. Ann Nutr Metab 1998;42:12-22.

61. Kovács A, Funke S, Marosvölgyi T, Burus I, Decsi T. Fatty acids in early human milk after preterm and full-term delivery. J Pediatr Gastroenterol Nutr 2005;41:454-9.

62. Lawrence RA. Storage of human milk and the influence of procedures on immunological components of human milk. Acta Paediatr Suppl 1999; 88:14-8.

63. Luukkainen P, Salo MK, Janas M, Nikkari T. Fatty acid composition of plasma and red blood cell phospholipids in preterm infants from 2 weeks to 6 months postpartum. J Pediatr Gastroenterol Nutr 1995;20: 310-5.

64. Klein CJ. Nutrient requirements for preterm infant formulas. J Nutr 2002;132:1395S-577S 